\title{
Bidirectional heart rate responses in rats associated with excitatory and inhibitory stimuli
}

\author{
JOHN W. HOFFMAN and ROBERT D. FITZGERALD \\ Department of Medical Psychology, Oregon Health Sciences University, Portland, Oregon 97201
}

\begin{abstract}
Following classical conditioning to a shock-reinforced tone $\mathrm{CS}\left(\mathrm{T}_{1}+\right)$, heart rate $(\mathrm{HR})$ of three groups of rats was examined in response to a new reinforced tone $\left(\mathrm{T}_{2}+\right)$ and a nonreinforced light $(\mathrm{L}-) \mathrm{CS}$ given during conditioned inhibition $\left(\mathrm{T}_{2}+\right.$ vs. $\left.\mathrm{T}_{2} \mathrm{~L}-\right)$, discrimination conditioning $\left(\mathrm{T}_{2}+\mathrm{vs}\right.$. $\mathrm{L}-$, or explicitly unpaired ( $\mathrm{T}_{2} / \mathrm{L}-\mathrm{vs}$. US alone) procedures. Decelerative HR reactions occurred to the reinforced $T_{2}+$ and $T_{2}+$ CSs. To the respective nonreinforced CSs, the conditioned inhibition group displayed diminished but sizable HR deceleration, the discrimination group showed near-zero responding, and the explicitly upaired group showed HR acceleration. Subsequent reversal conditioning to $\mathrm{L}$ was retarded in the conditioned inhibition and explicitly unpaired groups relative to the discrimination group. Group differences on combined-cue $\left(T_{1} / L-\right)$ trials were not found. Both the HR responses during inhibitory training and the reversal-conditioning impairments suggest that inhibition may have been established to $\mathrm{L}-$ in the conditioned inhibition and explicitly unpaired groups.
\end{abstract}

Cunningham, Fitzgerald, and Francisco (1977) reported that directionally opposite heart rate (HR) responses were produced in restrained rats by varying the contingency relation between a CS and a shock US. In the first phase of the study, excitatory classical conditioning produced a decelerative HR CR to a CS + that was consistently paired with the US. Subsequently, a subgroup of the same rats demonstrated an accelerative HR response to a different CS (CS-) that was given in an explicitly unpaired relation to the US. A second subgroup receiving truly random presentations of the CS- and US showed near-zero responding to $\mathrm{CS}-$. Later, the explicitly unpaired group exhibited retarded development of a decelerative HR CR to CS - when CS - was paired with the US during reversal conditioning. In keeping with contemporary treatments of conditioned inhibition (Wagner \& Rescorla, 1972), Cunningham et al. suggested that the opposing directions of the HR responses of the explicitly unpaired group to $\mathrm{CS}+$ and $\mathrm{CS}-$, and the impaired performance shown by this group during reversal conditioning, provided evidence that the explicitly unpaired CS - was inhibitory.

Although HR offers a naturally occurring abovezero-baseline level of activity for evaluating the capacities of excitatory and inhibitory stimuli to elicit opposite responses, HR direction in inhibitory paradigms other than the explicitly unpaired arrangement

This research was supported in part by Grants HL-222727 and HL-07374 from the National Institutes of Health. John Hoffman is presently at the Division of Behavioral Medicine, Harvard Medical School, Boston, Massachusetts. Reprint requests should be addressed to Robert D. Fitzgerald, Department of Medical Psychology, Oregon Health Sciences University, 3181 S.W. Sam Jackson Park Road, Portland, Oregon 97201. remains largely unknown. In the case of discrimination conditioning, which is thought to have some capacity to generate inhibition (Wagner \& Rescorla, 1972), instances of "inhibitory-like" HR accelerations to CS - were obtained in one study (Yamaguchi \& Iwahara, 1974), but not in another (Martin \& Fitzgerald, 1980). Decelerative HR responding occurred to $\mathrm{CS}+$ in both studies. Heart rate has apparently not been evaluated in the context of the conditioned inhibition paradigm, which many believe is the most powerful procedure for producing learned inhibition (Wagner \& Rescorla, 1972).

The purpose of the present experiment was to provide a comparison of the HR responses of restrained rats during conditioned inhibition, discrimination conditioning, and explicitly unpaired procedures. Assessments of the relative inhibitory strengths of the nonreinforced CSs within each condition were also made using special combined-cue and reversalconditioning tests for inhibition (Hearst, 1972).

\section{METHOD}

\section{Subjects}

Thirty naive, female, hooded Long-Evans rats $(250-300 \mathrm{~g})$ were used. They were purchased from Simonsen Laboratories of Gilroy, California, and were housed by the Department of Animal Care at the University of Oregon Health Sciences Center on a 12-h diurnal cycle with free access to food and water.

\footnotetext{
Apparatus

The rats were restrained in an inverted U-shaped Plexiglas holder manufactured by Narco Bio-Systems, Inc. Adjustable guillotine-type inserts were positioned in front of and behind each animal to hold it securely. The restrainer was placed in an Industrial Acoustics Corporation sound-isolation chamber that was equipped with a $7.5-\mathrm{cm}$ ventilation fan and an $8.3-\mathrm{cm}$ wall-mounted speaker
} 
through which white noise (75 dB, re $.0002 \mu$ bars) was delivered to mask extraneous sounds.

The electrocardiogram (ECG) was recorded on a Grass Model 5 polygraph from two 20-ga hypodermic needles that were inserted under the skin, one on each side of the rat's thoracic cavity. The number of heartbeats occurring in consecutive time intervals within a trial was tabulated automatically with an on-line system described previously (Fitzgerald, Vardaris, \& Teyler, 1968). The system contained a miniature microswitch whose arm was connected to the tip of the ECG pen. The position of the switch was adjusted so that it was activated by the $R$ wave of each QRS complex. The number of heartbeats was accumulated electronically, and the totals were punched on a Tally paper-tape perforator. The accuracy of the recording system was checked periodically, by substituting a $10-\mathrm{Hz}$ signal for the incoming ECG signal.

There were three 10 -sec CSs, two auditory and one visual. The auditory CSs were $85-\mathrm{dB}$ (re $.0002-\mu \mathrm{bar}$ ) tones delivered through separate $10-\mathrm{cm}$ speakers located directly in front of the rat. One tone $\left(T_{1}\right)$ was $500 \mathrm{~Hz}$ and was interrupted at a rate of $150 \mathrm{msec}$ on, $150 \mathrm{msec}$ off. The second tone $\left(\mathrm{T}_{2}\right)$ was $1.8 \mathrm{kHz}$ and was continuous. The visual CS was a flashing light (C) produced by activating a $28-\mathrm{V} \mathrm{dc} 1-\mathrm{cm}$-diam miniature lamp at a rate of $300 \mathrm{msec}$ on, $300 \mathrm{msec}$ off. The lamp was mounted in front of the animal near the speakers. The US was a .5 -sec $1.3-\mathrm{mA} 60$-cycle ac electric shock delivered through the ECG electrodes. The intensity of the shock was monitored by measuring the voltage drop across a $100-Q$ resistor in series with the animal. Trials were initiated automatically by a film-tape programmer.

\section{Procedure}

Three groups of 10 rats each received training in four successive phases. During Phase 1 , the three groups were given 24 paired conditioning trials with a CS-US interval of $10 \mathrm{sec}$, using $T_{1}+$ as the CS. In Phase 2, each group received a different inhibitory training procedure. The conditioned inhibition group was given 96 paired conditioning trials using $T_{2}+$ as the $C S$ and 96 unpaired trials of $\mathrm{T}_{2} / \mathrm{L}-$ in compound. The discrimination group received 96 paired $\mathrm{T}_{2}+$ trials and 96 unpaired $\mathrm{L}-$ trials. For both groups, paired and unpaired trials were given in a semirandom sequence with the restriction that no more than three trials of either type could occur consecutively. The explicitly unpaired group received 96 compound $T_{2} / L$ - trials and 96 US-alone trials in an alternating sequence, with the US occurring 70,90 , or $110 \mathrm{sec}$ after the CS. All groups were treated identically during Phases 3 and 4 . During Phase 3 , the groups were given two unpaired $T_{1}-$ and two unpaired $\mathrm{L}$ - trials followed by six $T_{1} / \mathrm{L}$ - combined-cue trials. The same sequence was then repeated, providing a total of 4 pretest $\mathrm{T}_{1}-$ trials, 4 pretest $\mathrm{L}-$ trials, and $12 \mathrm{~T}, / \mathrm{L}$ - trials. The fourth phase consisted of 52 paired conditioning trials, using $L-$ as the $\mathrm{CS}$ and the same 10-sec CS-US interval as used during original conditioning. The intertrial intervals within the various phases varied randomly among 150,180 , and $210 \mathrm{sec}$ (mean $=180 \mathrm{sec}$ ).

The four phases were carried out over 4 days. At the beginning of each day, the rats were allowed 15 min to adapt to the restrainer before the first trial was delivered. The $24 T_{1}+$ trials and 48 of the inhibitory trials of Phase 2 were given on Day 1. The remaining 144 trials of Phase 2 were administered over Days 2 and 3. The pretest, combined-cue, and reversal-conditioning phases occurred on Day 4.

Heartbeats were recorded during six successive measurement intervals on each trial. The first interval was $10 \mathrm{sec}$ in duration and occurred immediately preceding the onset of a trial. The remaining intervals were $2 \mathrm{sec}$ in duration and occurred during the CS. Difference scores were computed by subtracting the beat per minute (bpm) rate in the $10-\mathrm{sec}$ baseline interval from each of the rates in the 2 -sec intervals.

\section{RESULTS}

The HR responses of the three groups to $T_{1}+$ during original conditioning and to the reinforced and nonreinforced stimulus events during inhibitory training are shown in Figure 1. All groups showed similar decelerative HR CRs to $\mathrm{T}_{1}+$, with maximal decelerations occurring toward the end of $T_{1}+$. The changes in HR over intervals were significant $[F(4,108)=$ $20.83, \mathrm{p}<.001]$. During inhibitory training, the conditioned inhibition group continued to show HR decelerations to the new reinforced stimulus $\mathrm{T}_{2}+$ and to the nonreinforced compound $T_{2} / L-$, with differences in response magnitude in favor of $\mathrm{T}_{2}+$ developing over trials. A $2 \times 3 \times 5$ (type of CS $\times$ trials $\times$ measurement intervals) analysis of variance (ANOVA) on this group indicated that the overall difference between $T_{2}+$ and $T_{2} / L-$ was significant $[F(1,9)=$ $15.30, \mathrm{p}<.001$ ], as were the type of CS $\times$ trials interaction $[F(2,18)=4.17, p<.05]$ and the type of $C S$ $X$ intervals interaction $[F(4,36)=18.32, p<.001]$. The discrimination group also displayed HR decelerations to $T_{2}+$ during inhibitory training and on the initial block of trials, HR acceleration to $\mathrm{L}-$. On subsequent trials, responding to $\mathrm{L}$ - decreased toward baseline. A $2 \times 3 \times 5$ ANOVA on this group provided a significant type of CS effect $[F(1,9)=10.99$, $p<.001]$ and a significant type of CS $x$ intervals interaction $[F(4,36)=20.71, \mathrm{p}<.001]$. The response of the explicitly unpaired group to the $T_{2} / L-c o m-$ pound consisted of $\mathrm{HR}$ acceleration whose magnitude increased over trials. A $3 \times 5$ (trials $\times$ measurement intervals) ANOVA demonstrated that the intervals effect $[F(4,36)=4.19, p<.01]$ and the trials ef fect $[F(2,18)=3.55, p<.05]$ were both significant.

A comparison of the conditioned inhibition and discrimination groups in Figure 1 indicates that differential responding was greater in the discrimination group than in the conditioned inhibition group, due largely to differences in their respective responses to the nonreinforced CS. A $2 \times 2 \times 3 \times 5$ (groups $\times$ type of CS $\times$ trials $\times$ measurement intervals) ANOVA on these groups produced a significant groups $\times$ type of CS $\times$ trials interaction $[F(2,36)=6.41, p<$ $.01]$, indicating that the responses of the groups were reliably different. Separate groups $\times$ trials $\times$ measurement intervals ANOVAs demonstrated that the responses of the three groups to the unpaired stimulus events were all significantly different from each other. There was a significant overall groups effect among the three groups $[\mathrm{F}(2,27)=10.42, \mathrm{p}<.001]$, between the conditioned inhibition and discrimination groups $[F(1,18)=9.81, p<.01]$ and between the conditioned inhibition and explicitly unpaired groups $[F(1,18)=13.16, p<.001]$. For the discrimination vs. explicitly unpaired groups, there was a significant groups $x$ trials interaction $[F(2,36)=8.59, p<.01]$ and a significant groups $\times$ intervals interaction $[F(4,72)=2.98, p<.01]$.

The responses of the three groups on the $T_{1}-$ and $\mathrm{L}$ - unpaired pretest trials and $\mathrm{T}_{1} / \mathrm{L}$ - combined-cue trials are shown in Figure 2. On the pretest trials, 


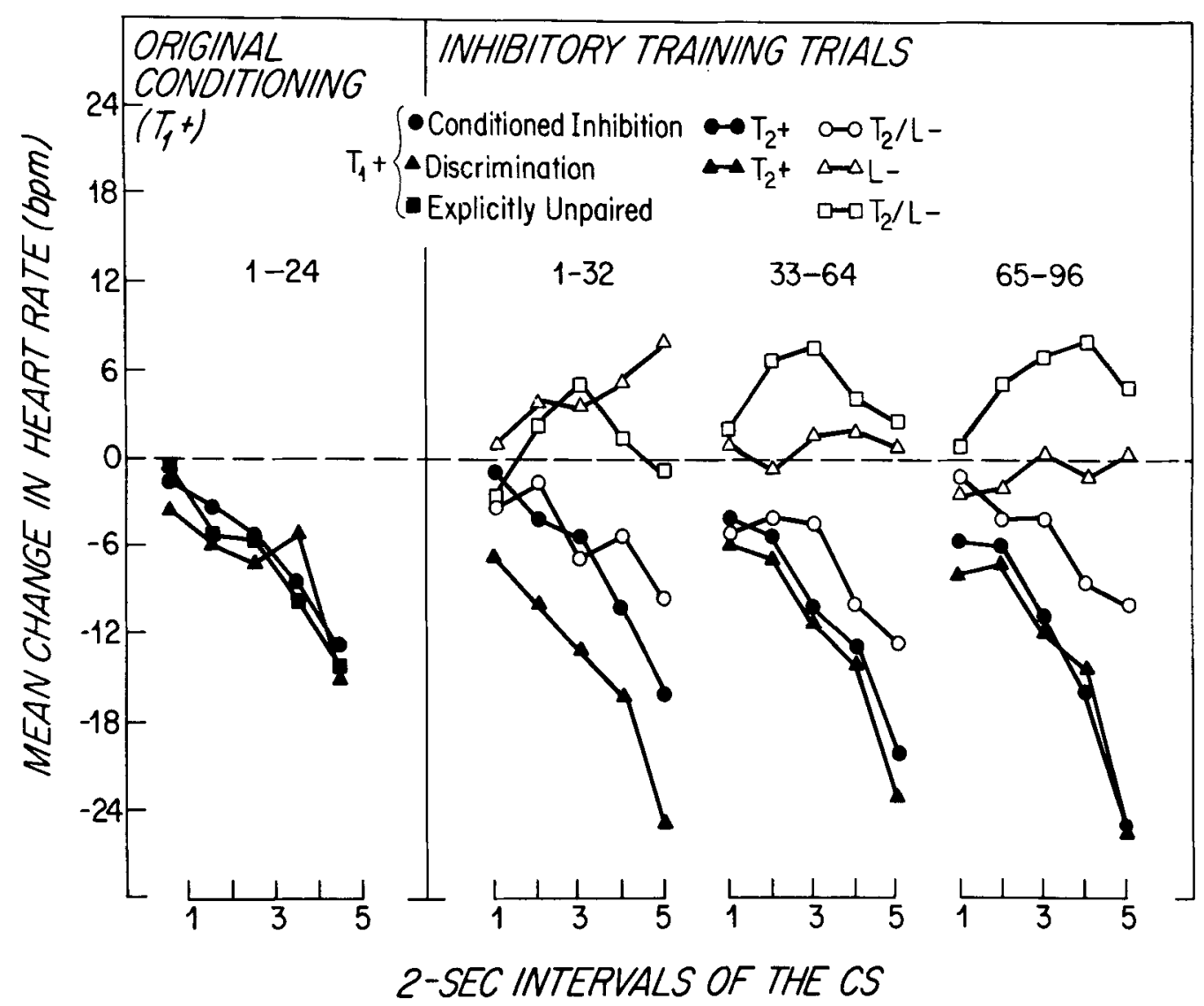

Figure 1. Mean HR changes of the conditioned inhibition, discrimination, and explicitly unpaired groups during excitatory conditioning (left panel) and inhibitory training (right panel) in successive 2-sec intervals of the CSs.

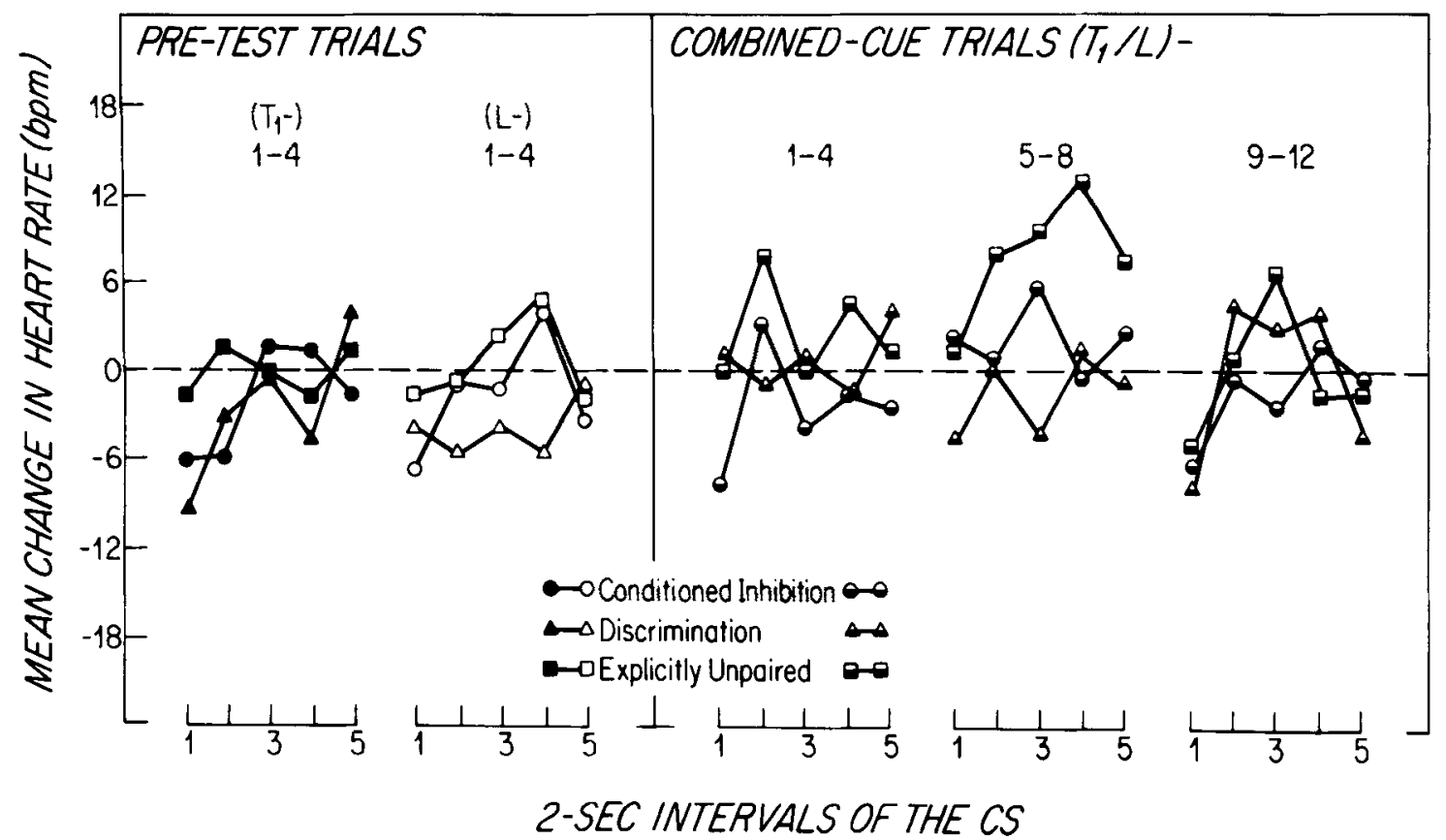

Figure 2. Mean HR changes of the three groups on the nonreinforced pretest trials (left panel) and combined-cue trials (right panel) in successive 2 -sec intervals of the CSs. 


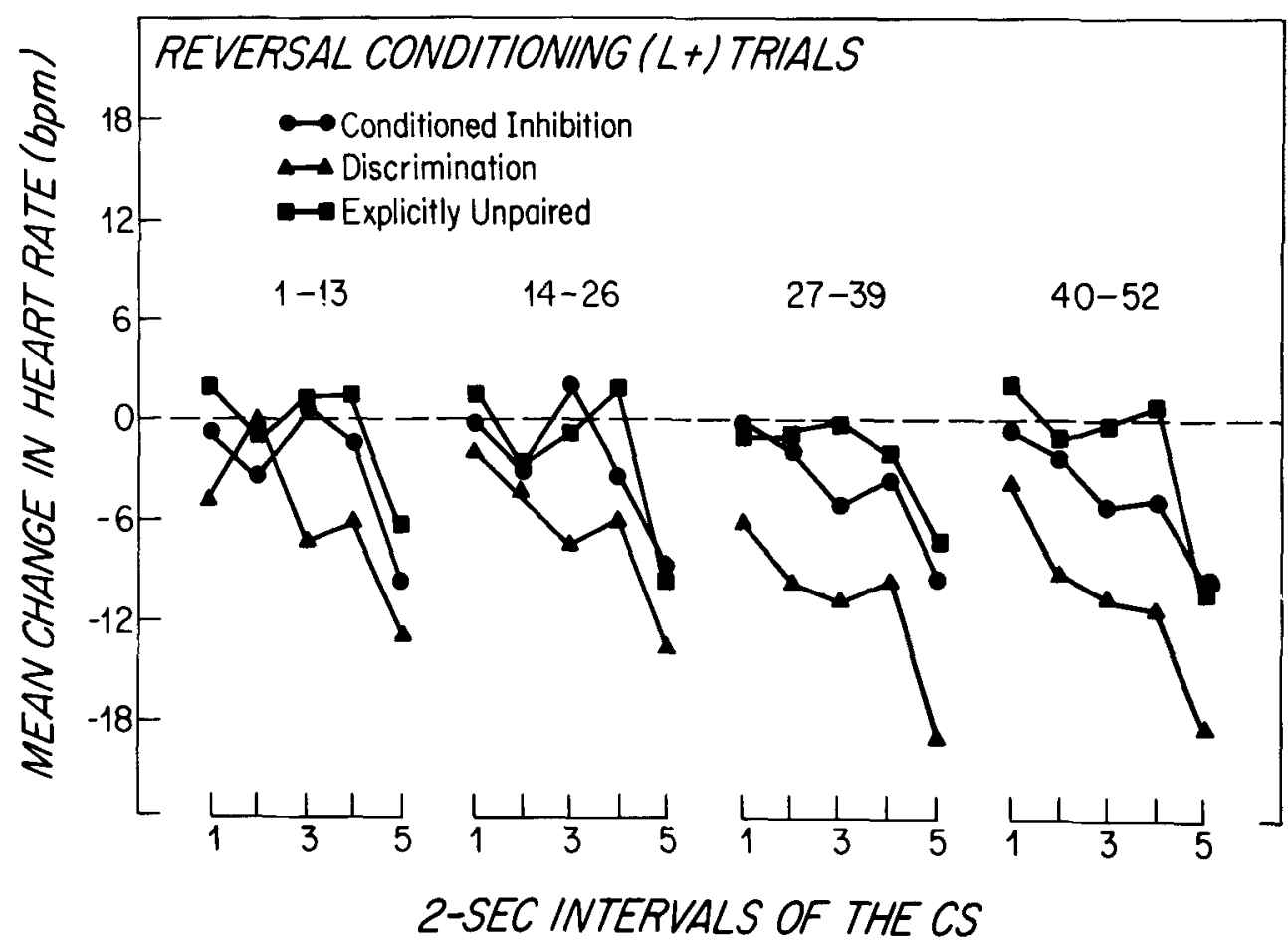

Figure 3. Mean HR changes of the three groups in successive 2-sec periods of $L+$ during reversal conditioning.

group responses were small-magnitude decelerations and accelerations. A $3 \times 2 \times 5$ ANOVA provided only a significant effect of measurement intervals $[F(4,108)=3.12, p<.05]$. Group responding on the combined-cue trials was similar and variable in direction except for the middle trial block, in which the explicitly unpaired group again displayed accelerative responding. A $3 \times 2 \times 5$ ANOVA showed that the groups $\times$ trials $\times$ intervals interaction was significant $[F(16,108)=2.10, p<.05]$.

Figure 3 shows the responses to reinforced presentations of $\mathrm{L}$ during reversal conditioning. All groups showed decelerative $\mathrm{HR}$ changes to $\mathrm{L}+$, which reached a peak at the end of the CS. The overall magnitudes of the responses of the conditioned inhibition and explicitly unpaired groups were similar to each other and generally smaller than those of the discrimination group. A $3 \times 4 \times 5$ ANOVA produced a significant groups effect $[\mathrm{F}(2,27)=4.02, \mathrm{p}<.05]$, confirming the reliability of the group differences. A subsequent Newman-Keuls test demonstrated that the discrim- ination group was significantly different from both of the other groups $(\mathrm{p}<.05)$.

Baseline HRs of the groups during each phase of the study are given in Table 1. From this table, it may be seen that HR in the explicitly unpaired group was generally lower than that of the other groups throughout the study. However, individual ANOVAs performed within each phase failed to provide any significant between-groups differences.

\section{DISCUSSION}

The main findings were: (1) during inhibitory training, the explicitly unpaired group showed persistent HR acceleration to the unpaired $\mathrm{T}_{2} / \mathrm{L}-$ compound, the conditioned inhibition group showed persistent HR deceleration to $T_{2} / \mathrm{L}-$, and the discrimination group showed temporary $\mathrm{HR}$ acceleration to $\mathrm{L}-$; (2) during reversal conditioning, acquisition of a deceleration HR CR to the previously unpaired $L$ - was retarded in the explicitly unpaired and conditioned

Table 1

Mean Baseline HR in Beats per Minute of Each Group During the Various Experimental Phases

\begin{tabular}{|c|c|c|c|c|c|c|c|}
\hline \multirow[b]{2}{*}{ Group } & \multirow{2}{*}{$\begin{array}{c}\text { Conditioning } \\
\mathrm{T}_{1}+\end{array}$} & \multicolumn{2}{|c|}{ Inhibitory Trials } & \multicolumn{2}{|c|}{ Pretest } & \multirow{2}{*}{$\begin{array}{c}\text { Combined Cue } \\
\mathrm{T}_{1} \mathrm{~L}- \\
\end{array}$} & \multirow{2}{*}{$\begin{array}{c}\text { Reversal } \\
\mathrm{L} \\
\end{array}$} \\
\hline & & Positive & Negative & $T_{1}-$ & L- & & \\
\hline $\begin{array}{l}\text { Conditioned Inhibition } \\
\text { Discrimination } \\
\text { Explicitly Unpaired }\end{array}$ & $\begin{array}{l}482 \\
474 \\
465\end{array}$ & $\begin{array}{l}484 \\
481\end{array}$ & $\begin{array}{l}482 \\
481 \\
468\end{array}$ & $\begin{array}{l}475 \\
474 \\
469\end{array}$ & $\begin{array}{l}478 \\
473 \\
470\end{array}$ & $\begin{array}{l}475 \\
471 \\
464\end{array}$ & $\begin{array}{l}483 \\
475 \\
472\end{array}$ \\
\hline
\end{tabular}


inhibition groups relative to the discrimination group; (3) baseline HR of the groups was not significantly different in any phase.

The finding that an accelerative $H R$ response developed across trials to $T_{2} / L-$ in the explicitly unpaired group during the inhibitory training phase, and that it was opposite in direction to the decelerative HR CR that occurred to the regularly reinforced $T_{1}+$ during the earlier excitatory training phase, agrees with the results of a previous study (Cunningham et al., 1977). Also in agreement is the fact that the subsequent acquisition of a decelerative $H R C R$ to $L$ in the explicitly unpaired group was impaired during reversal conditioning. Both outcomes are consistent with the view that the explicitly unpaired stimulus acquired inhibitory capacities (Rescorla, 1969).

Reversal conditioning to $\mathrm{L}$ was also retarded in the conditioned inhibition group even though the HR responses of this group to $\mathrm{T}_{2} / \mathrm{L}$ - during inhibitory training matched the decelerative direction of the HR CRs that were shown to reinforced $\mathrm{T}_{2}+$. Furthermore, there was no evidence of an accelerative reaction to $\mathrm{L}$ - in this group when $\mathrm{L}$ - was presented by itself on the pretest trials. However, the responses of all groups on these trials and on the combined-cue trials given immediately afterward were quite small and variable in direction. More vigorous responding might have occurred in this phase had additional trials with the US been given first. Nevertheless, finding a reversal-conditioning decrement in the conditioned inhibition group in the absence of accelerative responding to $L$ - suggests that $H R$ direction per se cannot be used as an index of conditioned inhibition.

The initial HR acceleration of the discrimination group to $\mathrm{L}-$ on the first block of inhibitory trials and its loss on subsequent trials can be viewed in two ways. First, the HR increase could have been an orienting response that eventually habituated. Some support for this possibility was provided by the fact that accelerative HR changes occurred to the first presentation of $\mathrm{L}-$. On the other hand, previous studies (e.g., Fitzgerald \& Hoffman, 1976) have repeatedly found that the rat's orienting HR reaction to an auditory stimulus is decelerative. Second, the acceleration may have been based on an inhibitory process that was lost due to the extinction of excitatory background cues that are thought to support the development of inhibition (Wagner \& Rescorla, 1972). According to this treatment, environmental elements in a discrimination paradigm may gain excitatory strength by being associated with the US on CS + trials. Extinction of excitation occurs as a discrimination is formed between CS+ and the environmental elements.

Similar reasoning can be applied to the persistent acceleration that occurred to $\mathrm{T}_{2} / \mathrm{L}$ - in the explicitly unpaired group, except that here background cues would remain excitatory by virtue of their association with the unsignaled US. In the case of the conditioned inhibition group, excitation necessary for inhibition to accrue to $\mathrm{L}$ - would be provided by giving the partially reinforced $T_{2}+$ in compound with $L-$. The fact that the HR deceleration of this group to the $T_{2} / L-$ compound was less than to $T_{2}+$ by itself can be viewed as evidence of the inhibitory strength of $L-$.

In addition to the notion of conditioned inhibition, the present findings also bear on several alternative hypotheses that have been offered to explain impaired reversal conditioning to a putative inhibitory CS-. One of these suggests that reversal conditioning may be retarded because prior nonreinforced presentations of a CS- during inhibitory training cause a reduction in attention or responsivity to CS- (Hearst, 1972). Evidence that the stimuli were noticed on the inhibitory trials in the current study was provided by the active responding to $T_{2} / \mathrm{L}$ - in the explicitly unpaired group and by the reduced level of HR deceleration in the conditioned inhibition group when Lwas given in compound with $T_{2}$. Although the discrimination group appeared not to react to $\mathrm{L}$ - during most of the inhibitory training, it nevertheless demonstrated the best reversal conditioning to $L$.

A second possibility for a reversal-conditioning decrement is based on the notion of a stimulus generalization decrement (Mackintosh, 1974). In the case of the explicitly unpaired and conditioned inhibition groups, reversal conditioning was the first phase of the study (except for the $\mathrm{L}$ - pretest trials) in which $\mathrm{L}$ - was presented by itself, whereas, for the discrimination group, L - was given alone repeatedly during inhibitory training. Thus, the former groups may have experienced greater stimulus change during reversal conditioning than the latter group, and this change could have impeded the development of their reversal CRs. Although this hypothesis cannot be ruled out, stimulus generalization decrement effects may not be expected to persist over the relatively large number of reversal conditioning trials used here.

A final explanation, which may have some merit, accounts for retarded reversal conditioning on the basis of competing responses that are learned during inhibitory training (Hearst, 1972). Because they were exactly opposite, it seems reasonable to assume that the accelerative reaction to $T_{2} / L-$ in the explicitly unpaired group could have competed with the development of the decelerative CR to $L$. Evidence that HR acceleration to an explicitly unpaired CS- may be mediated by autonomic processes different from those controlling decelerative CRs was obtained in a recent study using pharmacological blockade (Eskenazi \& Fitzgerald, Note 1). This study showed that the accelerative reaction to $C S$ - had a major sympathetic component, whereas a previous experiment (Fitzgerald, Martin, \& O'Brien, 1973) demonstrated that decelerative HR CRs to a CS + were mediated mainly by vagal influences. Response competition theory can 
also be applied to the reversal decrement in the conditioned inhibition group if it is assumed that increased sympathetic activity contributed to the observed reduction in deceleration when $\mathrm{L}-$ was paired with $T_{2}$ on the $T_{2} / L-$ compound trials.

\section{REFERENCE NOTE}

1. Eskenazi, B., \& Fitzgerald, R. D. Relative autonomic control of excitatory and inhibitory based changes in $H R$. Manuscript in preparation, 1981.

\section{REFERENCES}

Cunningham, C. L., Fitzgerald, R. D., \& Francisco, D. L. Excitatory and inhibitory consequences of explicitly unpaired and truly random conditioning procedures on heart rate in rats. Animal Learning \& Behavior, 1977, 5, 135-142.

Fitzgerald, R. D., \& Hofrman, J. W. Classically conditioned heart rate in rats following preconditioning exposure to the CS. Animal Learning \& Behavior; 1976, 4, 58-60.

Fitzgerald, R. D., Martin, G. K., \& O'Brien, J. H. Influence of vagal activity on classically conditioned heart rate in rats.
Journal of Comparative and Physiological Psychology, 1973, 83, 485-491.

Fitzgerald, R. D., Vardaris, R. M., \& Teyler, T. J. An online method for measuring heart rate in conditioning experiments. Psychophysiology, 1968, 4, 352-353.

He ARst, E. Some persistent problems in the analysis of conditioned inhibition. In R. A. Boakes \& M. S. Halliday (Eds.), Inhibition and learning. London: Academic Press, 1972.

Mackintosh, N. J. The psychology of animal learning. New York: Academic Press, 1974.

Martin, G. K., \& Fitzgerald, R. D. Heart rate and somatomotor activity in rats during signalled escape and yoked classical conditioning. Physiology \& Behavior, 1980, 25, 519-526.

Rescorla, R. A. Pavlovian conditioned inhibition. Psychological Bulletin, 1969, 72, 77-94.

Wagner, A. R., \& Rescorla, R. A. Inhibition in Pavlovian conditioning: Application of a theory. In R. A. Boakes \& M. S. Halliday (Eds.), Inhibition and learning. London: Academic Press, 1972.

YamagUchi, K., \& IwahaRA, S. Effects of chlordiazepoxide upon differential heart rate conditioning in rats. Psychophar. macologia, 1974, 39, 71-79.

(Manuscript received July 15, 1981;

revision accepted for publication September 9, 1981.) 